\title{
Friends of Design: Building a Support Community for Capstone Projects
}

\author{
Khoman Phang \\ Senior Lecturer, the Edward S. Rogers Sr. Dept. of Electrical and Computer Engineering, \\ University of Toronto \\ E-mail: kphang@eecg.utoronto.ca
}

\begin{abstract}
'Friends of Design' is a resource network developed to support capstone design projects. Our goal is to provide students with access to a broad community of students, staff, faculty, and professionals who are available to provide advice. This paper discusses the necessary people, organization, and resources.

The network is modeled after Malcolm Gladwell's book, the Tipping Point and its premise that successful social movements depend heavily on a few key people in the roles of Mavens, Connectors, and Salespersons. Mavens possess the technical expertise. Although faculty members naturally fit into this role, often, they have little time to assist undergraduate students, and so we draw upon alternative groups such as alumni, staff, graduate students, and professionals. Connectors provide the cohesion in the network. They link the various technical and social subcommunities. We desire a network that is not only broad in its technical knowledge, but also in its representation of the department comprised of students, alumni, staff, and faculty. Finally, salespersons are the persuaders and the leaders that drive the network, with juniors members helping bring inquiries forward and senior members enlisting fellow experts to provide responses.
\end{abstract}

Drawing from the Tipping Point, the network organization and communication model follows from the popular 'six degrees of separation' concept. Student inquiries are initially handled by Connectors, whose role is not to answer the inquiry outright but rather to act as conduits, forwarding the inquiry on, until it ultimately reaches an appropriate Maven. Promoting the Connectors' role in handling inquiries is crucial to making the network scalable, and should help promote interactions across disciplines and a stronger sense of community.

\section{Motivation}

The capstone design project provides engineering students with a rich learning experience and an opportunity showcase their ability to integrate and apply knowledge. Unfortunately, the traditional arrangement of having a single faculty supervisor is often not ideal since design projects often require knowledge and skills from a variety of technical areas. At other times such as when the supervisor is a clinical researcher, the supervisor may understand the target application but does not have the technical background to guide the implementation.

The 'Friends of Design' initiative is a recent effort to build a community and resource network to support design projects. Our goal is to provide students with access to a broad community of students, staff, faculty, and professionals who are available to provide advice and to connect students with other experts. As one of the largest engineering departments in Canada, we clearly have a large knowledge base on hand. What is less clear, however, is how our students can easily access this knowledge. How can we begin to cultivate a sense of this community within our department, and eventually expand the community beyond our department and into the faculty, university, and even other institutions and industry?

In Malcolm Gladwell's book, the Tipping Point[1], he argues that it is possible to cultivate social movements or 'epidemics' given the proper people, a memorable message, and the right context or social circumstance. This paper explores these ideas in the context of developing the Friends of Design and discusses the necessary people, organization, and resources. 


\section{Members and Roles}

Described as the Law of the Few, Gladwell argues that successful social movements depend heavily on a few key people in the roles of Mavens, Connectors, and Salesmen (which I use in a gender neutral sense). In our context, Mavens are the technical experts, Connectors are the people that bridge the various subcommunities within and outside the department and Salesmen are the persuaders and leaders that drive the network, with juniors members encouraging student inquiries and senior members encouraging faculty participation and enlisting new members.

Of the three roles, Mavens, the technical experts, are naturally the most readily available members in an engineering department. Our large department has many renowned faculty to draw from. Unfortunately, faculty often have limited time to interact with undergraduate students, and so we are drawing upon our staff, graduate students, and student clubs for technical expertise. Staff, including lab managers and technicians, are a real asset given their experience, practical knowledge, and frequent interaction with students. Graduate students are also an invaluable resource. They are often very enthusiastic, and in general have a strong affinity with their undergraduate counterparts. We are also reaching out to our alumni and to industry professionals who play a crucial role in bridging the knowledge gaps, especially in areas such as engineering standards, practical applications, applied knowledge, and skills.

If the presence of Mavens alone was sufficient, networks such as Friends of Design would probably form naturally. This is not so in practice, and that suggests the important role that Connectors play. Connectors are the people who have a broad network of contacts in different groups. The specialization which chararacterizes modern research tends to cultivate experts or Mavens but not Connectors. Often, engineering departments tend to be organized along research areas, much like silos that are isolated from each other. In addition, the department is comprised of many distinct subcommunities including faculty, researchers, lecturers, staff, students from different graduation years. An exceptional Connector would know many people from different research groups, some outside of engineering entirely, and would interact with staff, faculty, and students alike.

Naturally, Connectors should be representive of the cross section of our department. There should be faculty representation from each research group (ie. through the research group chairs). As with Mavens, graduate students stand out as an excellent Connector candidates. Their frequently interact with undergraduate students in their role as teaching assistants, and often have social ties through student societies and clubs. Graduate and undergraduate students involved in professional or technical associations and clubs such as Engineers without Borders, IEEE, and the Solar Car Race team are also natural candidates. Once the students graduate, they can participate as alumni to help connect the department and school with industry.

Finally, salespersons are the persuaders and the leaders that drive the network, with juniors members helping bring inquiries forward and senior members enlisting fellow experts to provide responses. While helpful, Salesmen are probably not critical as Mavens or Connectors. Since we are developing a support service, the function of salesman is not so distinct from that of the Connector, and there is no need to sell the network beyond making sure that students are aware it exists for them to access, and that faculty and graduate students and other potential members are aware that they are welcome to participate.

\subsection{Our message and Organization}

In the Tipping Point, Gladwell argues that the message matters as much as the messengers (people) and that the message should 'stick', in other words, be memorable and resonate with the audience. The network title 'Friends of Design' itself is intended to convey the social dynamic of this network. We are tapping into the basic desire of people to communicate and to belong to a community. As such our message to potential members is as follows:

If you are interested in meeting others with a common interest and are willing to share your knowledge, then we want you. We will accept whatever time you can give. We want you to have fun and to find the experience rewarding.

Networking comes as a natural result of introducing students to other members. Members with other faculty, staff, students, alumni, industry professionals, and of course, the inquiring students. This cross section of groups is illustrated in Figure 1. The inverted pyramid illustrates how members typically begin at the bottom and how the narrow interaction can increasingly be expanded up and out as members become more active in the network. Doing so helps members develop their personal leadership skills and establish a network for their future careers. This is not an attention-seeking, Donald Trump "Apprentice" form of leadership, but one that remains technical, 
supportive, and relevant to most developing engineers. Linking is also a key feature in this interaction: students who seek help observe how help is provided and are encouraged to eventually join the network and 'pay forward' by helping others in return.

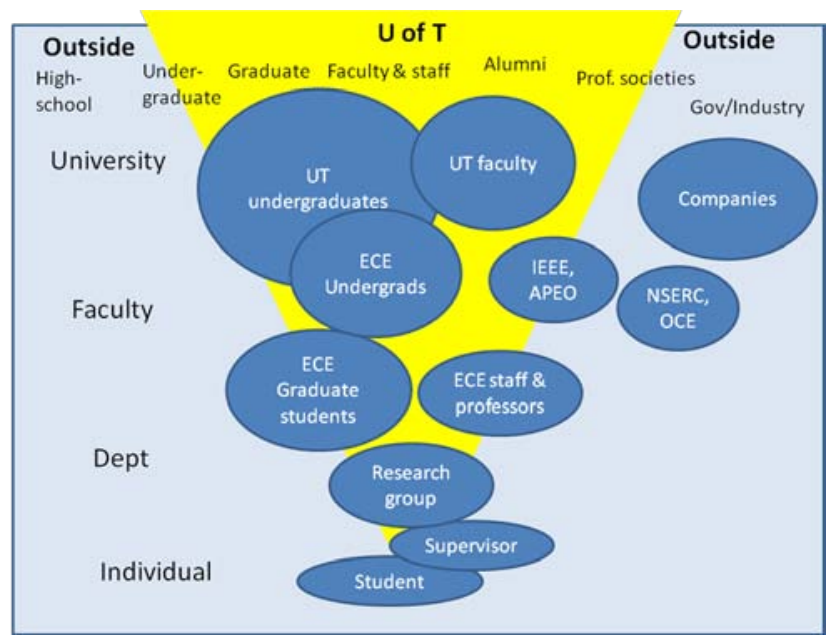

Figure 1: Pyramid of interaction and groups.

Figure 2 shows another way to illustrate the development of leadership. The pyramid conveys how the majority of members act as Mavens, providing technical guidance in their personal areas of expertise. Members begin at the bottom and work their way up, increasingly becoming Connectors as their familiarity with the network increases, first as a Local Connector for the peer group, and eventually as a Global Connector that spans groups.

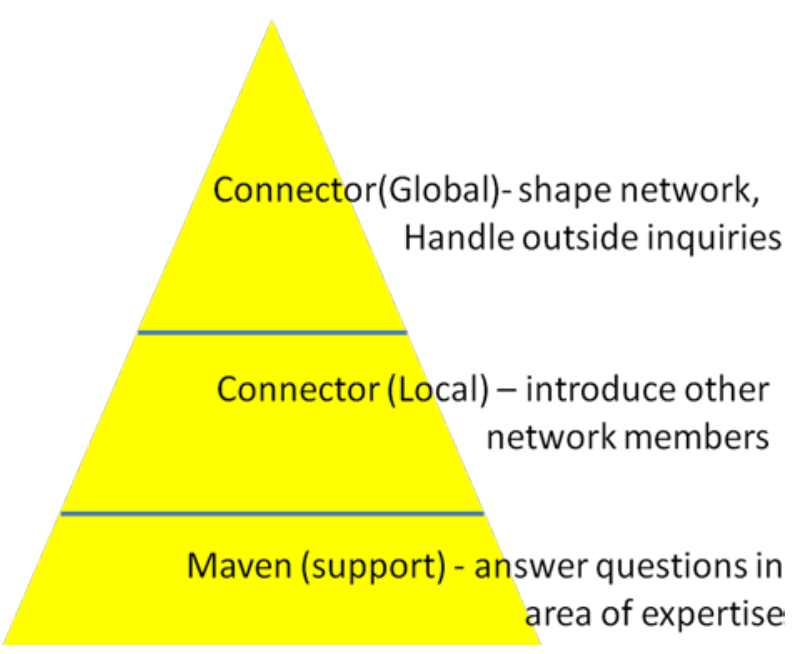

Figure. 2 Network organization and involvement

\section{Context: the Social Factor}

After the messengers and the message, Gladwell's final point is the Power of Context and how human beings and human behaviour are affected by our environment. If we are to be successful, the context of our interactions must support our message. For the Friends of Design, this implies helping students as a group and in an environment that is condusive to social interaction.

Our primary forum for meeting and helping students is in "Meet and Greet" sessions which we plan to schedule at various points in the design cycle of the design projects. Students are invited to come out and meet with the Friends of Design. Friends of Design Members representing the various groups are present and spread out through the room in a manner similar to a convention as shown in Figure 3. Members of the network are reminded to let the students drive the interaction, and to keep the conversation short and to keep the students moving.

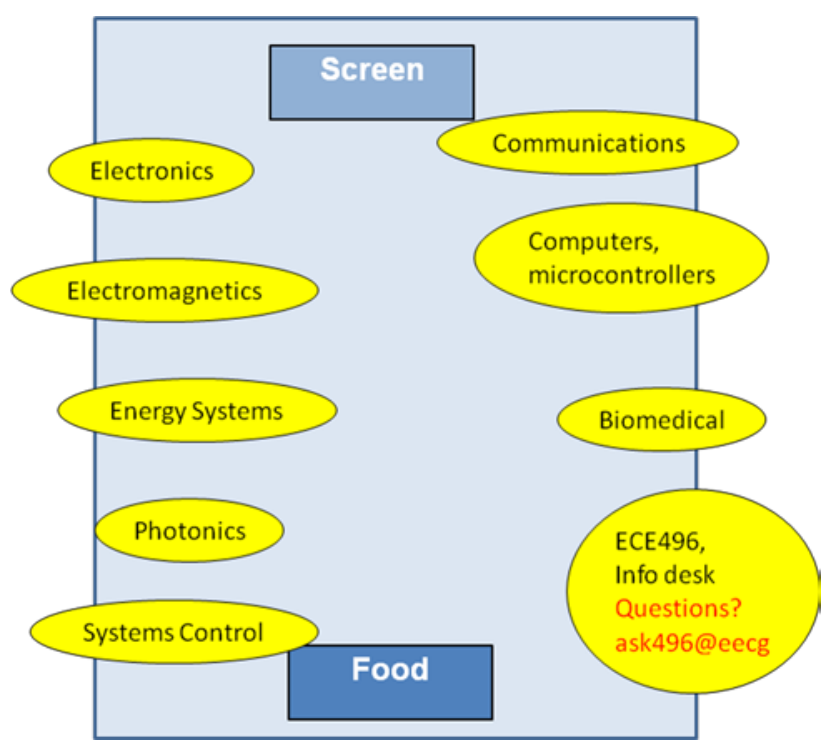

Figure 3: Sample room layout for "Meet and Greet” session.

The communication model follows from the popular 'six degrees of separation' concept, where student inquiries are initially handled by Connectors, whose role is not to answer the inquiry outright but rather to act as conduits, forwarding the inquiry on, until it ultimately reaches an appropriate expert. From there, the goal is not to dwell on giving students solutions, but rather to provide them with ideas, and to introduce them to other network members who could be of help. 
The hope is to expose both the students and Friends of Design members to a variety of dynamic interactions in a short span of time, thus succeeding in making it both helpful and social, and giving students leads to follow up on. Email and other electronic networking platforms such as Facebook or LinkedIn can be used to follow up but direct face-to-face communication is preferred when possible. Promoting the Connectors' role in handling inquiries is crucial to making the network scalable, and should help promote interactions across disciplines and a stronger sense of community.

\section{Other Resources}

We are developing a number of services to help support the Friends of Design. First, we have an online member database which members can use to create a personal profile which is then available to other members when they are handling student inquiries. We are also developing a wiki site as a forum for the Friends of Design to provide general technical information and advice regarding some of the most commonly encountered issues and problems. We are also encouraging members to present targeted workshops on specific topics such as microcontroller programming and PCB layout for students during the year.

To date, we have signed up about 70 members with representatives from industry, staff, alumni, current students, and faculty. We held a Meet and Greet session in March which was well received and helped get next year's design project teams off to an early start. Companies with an interest to strengthen ties to the department have also expressed an interest in participating.

\section{Conclusions}

We have outlined our Friends of Design network and how we have used the concepts from the book the Tipping Point to guide its development. We believe the network as proposed is scalable, and can be expanded across disciplines, into industry, and across universities. Our eventual goal is to foster new collaborations in the capstone design course and to give our students exposure to a much broader range of current, innovation projects and problems to solve.

\section{References}

[1] M. Gladwell, The Tipping Point: How Little Things Can Make a Big Difference, Little, Brown and Company, New York, 2000. 